\title{
BELIEFS OF GREEK SPORT VOLUNTEERS ABOUT THEIR COMPETENCIES IN VOLUNTEERING
}

\section{Olga BOPOTA $^{1 *}$, Andreas LOUKOVITIS ${ }^{1}$, Virginia POLITI ${ }^{1}$, Theofylaktos ANASTASIADIS, Vassilis BARKOUKIS ${ }^{1}$}

\author{
${ }^{1}$ Aristotle University of Thessaloniki, Faculty of Physical Education and Sport Science, Thessaloniki, Greece \\ *Corresponding author: olgabopo@phed.auth.gr
}

https://doi.org/10.35189/dpeskj.2020.59.3.9

\begin{abstract}
In volunteering, the keyword is "donation", and the historical evolution of volunteering is directly linked to "selfless charity". Sport is largely based on volunteering. This paper extends knowledge of the nature of sport volunteering by exploring the perspectives of sport volunteers based on self-reported questionnaires. The sample involved 192 volunteers and 6 volunteers' coordinators from both public and private sport organizations in Thessaloniki, a city in northern Greece. A 42-item self-reported questionnaire was administered to measure participants' perspectives on their competencies in the volunteering field. The internal reliability (Cronbach's alpha) for the perspectives on volunteering scale from volunteers and volunteers' coordinators was high $(a=.96)$. Regarding the evaluation of participants' beliefs about their competencies in volunteering, results showed that they had a positive perspective. The results of the analyses demonstrated no significant differences between males and females in their beliefs about competencies in volunteering. In addition, the analyses showed no significant differences in participants' beliefs about their competencies between the type of involvement (volunteer vs volunteer coordinator) and years of involvement. On the other hand, the results showed statistically significant differences in participants' beliefs based on their educational level and their role in the sport organizations. The findings of the present study provide valuable information on the beliefs about competencies in volunteering that sport organisations can use to empower volunteers and make them more effective in offering their services in sport organizations.
\end{abstract}

Keywords: volunteering, sports, beliefs, competencies.

\section{Introduction}

The idea of volunteering has at its core a willingness to contribute to the community as a whole, and in particular, as Wilson (2000) describes the concept of voluntary work, a display of freely given time to benefit others. In volunteering, the keyword is "donation", and the historical evolution of volunteering is directly linked to "selfless charity". When the term "volunteering" first appeared in 1750, it referred to civilians offered military service in emergencies, and charitable activity of religious organizations was a later expression of it (Cnaan et al., 1996). Nowadays, the concept of volunteerism encompasses a wide range of social activities that benefit indirectly or directly different social groups as well as the community as a whole.

Hence, the term "volunteer" has become an issue of public debate and received researchers' attention but it remains ambiguous in an international context. The confusion surrounding this term stems from its use as a generic term in English where it covers different realities and its different use in other languages where it is understood more specifically (e.g. for volunteers at sport events). For example, many persons who voluntarily work for a sport organization do not consider themselves to be a volunteer even if their activity complies with the criteria that are typically used for a definition (Steinbach et al., 2012). 
The development of volunteering is linked to a number of environmental factors as well as to the institutional framework, which determine to a large degree the form, extent and type of voluntary work provided (Anheier \& Salamon, 1999). In more developed societies, greater supply of volunteering is generally to be found (Salamon \& Sokolowski, 2001). As Wilson (2012) indicated, modernisation brings new forms of volunteering. The broader changes in society in recent decades reflect in the forms of volunteering (Lorentzen \& Hustinx, 2007). Specifically, it is common to distinguish between traditional and modern forms of volunteering. The social and cultural transformations have shaped the demand and supply of voluntary services, as well as their form (Hustinx, 2008). Traditional volunteers in the past tended to work at regularly scheduled intervals or on an ongoing basis. On the other hand, today's actual circumstances point to the need for the type of volunteering that is more specialised, more flexible and without an ongoing commitment (Anheier \& Salamon, 1999; Rehberg, 2005).

This change is explained by the development of a modern individualistic everyday culture, which is opposed to practices of reciprocity and the sense of belonging that characterises more traditional organizations. Today, volunteers are increasingly offering specific work hours and maintaining more relaxed communication and collaboration networks with other volunteers. This is described by Hustinx and Lammertyn (2003) as a "win-win" relationship for the benefit of both volunteers and organizations. It provides more efficient and specialised work especially when needed (Hustinx \& Lammertyn, 2003; Edwards, 2004; Hustinx et al., 2011).

In recent years, these forms of temporary or "episodic" volunteering (Dunn et al., 2015) have been widely disseminated and several studies have been relatedly conducted. These new types include "Blitz Volunteering", the recruitment and mobilisation of a large number of volunteers for the purpose of a particular activity, and "Drop-in Volunteering", that is the contribution, without particular individual planning and for a short period of time, to the completion of a long-term project (Polyzoidis, 2006).

According to Smith et al. (2010), volunteering can make a significant contribution to the community. With respect to the sport sector, the voluntary action is a large contributor since sport movement mainly relies on volunteers (Gravelle \& Larocque, 2005). Particularly in the sport context, volunteering in sports clubs has been recognised as of great importance to provide opportunities for people to engage in volunteering (Byers, 2009). Besides, Sport England (2003) acknowledged a profound impact of volunteer support on sport. Furthermore, the crucial role of voluntary programmes in elite sport is indicated by many researchers (e.g. Green \& Oakley, 2001).

According to the European Commission's Study on Volunteering in the European Union, "the sport sector is the largest voluntary, non-governmental organization activity throughout Europe with the most volunteers involved" (GHK, 2010, p. 34). The Nice Declaration (European Council, 2000) highlighted the important role of volunteering in sport and requested Member States to "encourage voluntary services in sport by means of measures providing appropriate protection for and acknowledging the economic and social role of volunteers, with the support, where necessary, of the Community".

Sport is largely based on volunteering. In addition, as the statistical data indicate, volunteering offers an opportunity for youth engagement in Europe. In fact, 24\% of European 
citizens over 15 work voluntarily, and $24 \%$ of volunteers work in the field of sport and physical activity. According to the 2013 Eurobarometer, there were 35 million sport volunteers (7\% of the total population) in Europe (European Commission, 2014). It is well documented that sport and physical activity are considered as an active and integral part of society and are mainly based on volunteering. The role of volunteer involvement in sport is well established in Greece, too. Examples include top sporting events and their support of volunteers in numbers. In 2004, at the Olympic and Paralympic Games held in Athens, 45,000 and 15,000 volunteers, respectively, were recruited, trained, and deployed.

Regarding sport volunteering as a phenomenon, it has permeable boundaries and spans a wide variety of activities, organizations, and sectors. It emerges as a social phenomenon that is very relevant today and is worthwhile to be studied. Although it continues to be a construct with multiple definitions, there is a widely accepted consensus on the criteria that describe the concept of volunteering: (a) it is undertaken out of a person's free will, (b) without concern for financial gain, (c) has no professional character, (d) is developed in the framework of non-profit, non-governmental organizations and (e) is for the benefit of the community or a third party (GHK, 2010). A definition of volunteering that outlines the above criteria is the following: "activities or work that some people willingly do without pay to promote a cause or help someone outside their household or immediate family" (International Labor Organization, 2007, p. 12).

A vast amount of research investigating the motivation to participate and volunteer in sport supports that every volunteer is unique with respect to motives, expectations, beliefs, and skills. According to GHK (2010), the factors that motivate individuals to volunteer vary considerably between individuals, age groups, sectors, and voluntary activities. Also, it has been highlighted that the factors that motivate young people to volunteer vary between countries (Smith et al., 2010). Researchers describe several overlapping categories of motivations to become a sport volunteer, such as values and altruism (e.g. Stebbins, 1996; Cuskelly \& Harrington, 1997), belonging and sociability, progress and change, interest in a cause or activity (e.g. GHK, 2010), personal and career development (e.g. Kulik, 2006), recognition and status (e.g. Fairley et al., 2007), and passion for (a specific) sport. Ringuet (2012) suggests that people's motives to volunteer for sport events are: (a) to play leadership roles, (b) to use existing skills and qualifications, (c) to find a sense of belonging, (d) to make new friends and feel enjoyable experience, (e) to feel that their input is valued by the organization, (f) to contribute to society, (g) to contribute to the organization and see inside the event. In addition, according to researchers, all volunteers in sport and recreation adopt four values that include generosity, love of sport, social connection, and appreciation (Sport and Recreation New Zealand [SPARC], 2006).

Apart from volunteers' motives, their profile considers biographical criteria (age, education, gender, family, etc.) (Nichols et al., 2012) as well the previous relationship between the volunteer and the sport organization (Steinbach et al., 2012). Sport Wales (2010) identified four key volunteer profiles: Students, Sport lovers, Parents and Skilled volunteers. Students are often motivated by self-development, seeking to enhance their skills and gain work experience. Sport lovers are motivated by a passion for their sport. Parent involvement in volunteering follows the child rather than the sport and they are motivated to spend time 
with and support their children. Skilled volunteers have specific skills, knowledge, or expertise in an area where not all volunteers could help out.

Volunteer involvement lies "at the very heart of any truly successful sporting event. Volunteers can provide the most basic of labour (e.g. handing out water and prize bags, setup and clean-up) and can also be a great source of expertise needed by organisations" (Ringuet, 2012, p. 155).

In particular, the typical sport event volunteers' roles include marketing, catering and hospitality, media roles, team management, volunteer supervision and management, venue management. crowd control, finance and budgeting, first-aid provision, event operations, risk management and registration (Ringuet, 2012).

Two groupings of sport volunteers are evident: those who hold managing, governing or administrative roles and those who participate in operational roles such as coaches, team managers and event organizers; both sets of roles are integral to the operation of sport clubs and events (Ringuet-Riot et al., 2014).

Pearce (1993) was the first to coin the term 'core' volunteer to describe the involvement and commitment levels of volunteers in non-profit organizations. Cuskelly et al. (2006) have applied this conceptualisation to sport volunteers and argued that core volunteers usually hold a formal office, often as a board or committee member, are seen as leaders and generally assume higher levels of involvement and commitment. Volunteers who engage with operational roles, such as scorers/timekeepers and medical support volunteers, are described as peripheral volunteers; they tend to commit less time and can be classified as steady or occasional contributors whose involvement and commitment levels are lower than those of core volunteers (Pearce 1993).

The above evidence indicates that volunteering is a worldwide phenomenon (Butcher \& Einolf, 2016) that can take a variety of forms (e.g. Marková, 2018). According to Smith (2000), volunteering can be seen, in a different context, as a 'flat-earth map'. In order to achieve its objectives, several aspects should be changed. Fortunately, the contemporary developments have created new perspectives for volunteering. In particular, the strategic plan for volunteering and the voluntary sector at a national level can be more comprehensive by the use of new information and material that is constantly developing. Researchers and stakeholders now have the opportunity to adopt new and innovative methodologies. In addition, changes in the culture of volunteering provide the opportunity to design a legal and regulatory framework to support volunteering - especially concerning the protection of volunteers. Finally, nowadays, more and more people are interested in volunteering and hence it is easier and more possible that it was in the past to attract funding and resources (Lough et al., 2011).

This paper extends knowledge about the nature of sport volunteering by exploring the perspectives of sport volunteers based on self-reported questionnaires. In particular, the present study aimed at determining competencies in the volunteering field. The main objective of the study is to examine the level of skills that volunteers or volunteers' coordinators believe they have for the development of the actions they take in their organizations. A secondary objective of this study is to evaluate participants' beliefs about their competencies in volunteering based on their gender, educational level, role in the organization and years of involvement in volunteering. 


\section{Methodology}

\section{Participants}

Participants in this study were recruited from both public and private sport organizations in Thessaloniki, a city in northern Greece. The sample involved 192 volunteers (61 men and 131 women) and 6 volunteers' coordinators ( 2 men and 4 women). Volunteers averaged 23.81 years of age ( $\mathrm{SD}=7.28)$, and volunteers' coordinators averaged 34.83 years of age (SD $=10.57$ ). All participants offered their voluntary actions in the context of these organizations.

\section{Measure}

A 42-item self-reported questionnaire was administered to measure participants' perspectives on their competencies in the volunteering field. Some examples of items from the scale are: "I am able to promote objective evaluation designs for each project in which I take part" and "I am able to build networks with other institutions and external professionals". Responses were recorded on a five-point scale ranging from 1 (not at all) to 5 (very much). The internal reliability (Cronbach's alpha) for the perspectives on volunteering scale from volunteers and volunteers' coordinators was high $(\mathrm{a}=.96)$.

\section{Procedure}

Sport organizations were contacted and the aim of the study was described to the administrative board. Following the permission of the administrative board, volunteers or volunteers' coordinators were briefed about the project and its objectives and informed consent was requested from those wishing to participate. Oral instructions were given to participants regarding the completion of the questionnaire. Participants were also reminded about voluntary participation. In addition, they were informed that the provided data were anonymous and confidential and would be used only for this research. Also, they were encouraged to ask any questions regarding the understanding/comprehension of the questionnaire items.

\section{Data analysis}

Internal consistency of the questionnaire was tested using Cronbach's alpha coefficients. Independent samples t-test analysis was used to assess differences in participants' beliefs about their competencies in volunteering based on their gender, educational background, role in the sport organizations and years of involvement in volunteering. The equality of variances was assessed by Levene's test. The statistical significance was set at .05. The SPSS statistical software - version 24 was used for the statistical analyses. 


\section{Results}

\section{Descriptive statistics}

Of the total sample, 63 participants were men and 135 participants were women. They range in age from 15 to 63 years old. Their mean age was 24.15 years ( $\mathrm{SD}=7.61)$. Most of them $(83.3 \%)$ had a university degree, while a small percentage $(1.5 \%)$ had completed primary or lower secondary education. With respect to their role in the sport organization, 192 of them were volunteers and 6 participants were volunteers' coordinators. The mean score of their years of involvement in volunteering was $2.80(\mathrm{SD}=3.38)$.

\section{Self-reported beliefs about competencies in volunteering}

Regarding the evaluation of participants' beliefs about competencies in volunteering, results showed that they had a positive belief on their competencies. Particularly, the mean item score was 4.25. This value represents positive beliefs of volunteers and volunteers' coordinators about the level of skills they have for the development of the actions they take in their organizations. The highest mean item score was $4.75(\mathrm{SD}=0.53)$ and corresponds to the item 21, "I respect the rules of the institution". The lowest mean item score was 2.77 (SD = 1.39) and corresponds to the item 12, "I am autonomous in decision-making".

As for the comparison between males' and females' beliefs about competencies in volunteering, the mean of beliefs for males was 4.19 ( $\mathrm{SD}=0.61)$, while it was 4.28 ( $\mathrm{SD}=$ 0.58) for female responders. Levene's test indicated equal variances for the beliefs of men and women $(\mathrm{F}=0.767, p=.38)$. A t-test assuming homogeneity of variance showed no statistically significant differences in the beliefs of male and female participants about competencies in volunteering, $\mathrm{t}(196)=-.931, \mathrm{p}>.05$, Hedges's $\mathrm{g}=0.15$.

Based on participants' educational background, the mean score of those with a university degree was $3.88(\mathrm{SD}=0.60)$, and the mean score of those without a university degree was 4.31 ( $\mathrm{SD}=0.57)$. Levene's test indicated equal variances for the beliefs of those with and without a university degree $(\mathrm{F}=0.313, p=.58)$ and a t-test assuming homogeneity of variance was computed. It was found that there were statistically significant differences in participants' beliefs based on their educational level, $\mathrm{t}(196)=-3.549, \mathrm{p}<.05$, Hedges's $\mathrm{g}=$ 0.72 .

When comparing the participants' beliefs based on their role in the sport organizations, the results showed statistically significant differences between volunteers and volunteers' coordinators, $\mathrm{t}(6.132)=-3.174, \mathrm{p}<.05$, Hedges's $\mathrm{g}=0.74$. Since Levene's test indicated unequal variances for the beliefs of volunteers and volunteers' coordinators $(\mathrm{F}=4.636, p=$ $.03)$, the above t-test not assuming homogeneity of variance. The mean of beliefs for volunteers was $4.24(\mathrm{SD}=0.59)$, while it was $4.67(\mathrm{SD}=0.32)$ for volunteers' coordinators.

With respect to the years of involvement in volunteering in sport organizations, the mean score of those who offer their voluntary action for five years is 4.27 ( $\mathrm{SD}=0.58$ ), while the mean score of those who are volunteers for more than five years is 4.09 ( $\mathrm{SD}=0.69$ ). Levene's test indicated equal variances for the beliefs of all participants based on their years of involvement in volunteering $(\mathrm{F}=1.799, p=.18)$. A t-test assuming homogeneity of 
variance showed no statistical differences in the beliefs about volunteers' competencies between the two groups, $\mathrm{t}(193)=1.289, \mathrm{p}>.05$, Hedges's $\mathrm{g}=0.30$.

\section{Discussion}

The present study aimed to detail the phenomenon of sport volunteering by identifying the perceived competencies of volunteers or volunteers' coordinators in sport organizations. In addition, the study identified how volunteers and volunteers' coordinators perceived their skills in offering voluntary action based on their characteristics. In particular, we tried to investigate if the perceptions of volunteers or volunteers' coordinators about their competencies were differentiated based on their gender, educational level, role in the organization and years of involvement in volunteering. A self-reported questionnaire was used to examine the above goals.

Our results suggest that volunteers and volunteers' coordinators have positive beliefs about the level of skills they have for the development of the actions they take in their sport organizations. According to our data, all participants shared these positive perceptions about their competencies. This means that both volunteers and volunteers' coordinators believe that they have the skills required to be effective and productive in their voluntary actions. These findings are similar to findings made by Misener et al. (2010). In their study, it was evident that almost all participants believed that they were making a contribution or difference to their sport organizations. The most frequent means of doing so was through their own skills and knowledge, which were discussed by the majority of the participants.

Furthermore, participants in our study identified the respect of the organization's rules as their greatest skill. This shows that they consider themselves to be disciplined and they think that they are able to follow the instructions given to them. This personality characteristic is really important for volunteers, as they need a lot of self-discipline to be effective contributors to the organizations. However, in contrast to the above finding, participants in another study described rules and policies as the negative aspects of their volunteer experience (Misener et al., 2010).

In addition, our participants recognized autonomous decision-making as their less developed skill. According to this finding, they feel that they are not in control over their actions and thus cannot act on their own terms. They rely on the directions of external factors, that is the senior executives of the sport organizations. This may be due to the fact that organizations do not give volunteers the opportunity to take initiatives. Usually, within the organizations, there are no favourable conditions to ensure that volunteers take charge and are proactive. Hence, volunteers are expected to feel that they do not have free of will. In line with our study, Misener et al. (2010) found that taking initiative was noted by a few participants and thus represented a more unique means of making a contribution to their organization.

The study also revealed that there were not differences in the beliefs of volunteers or volunteers' coordinators about their competencies in volunteering based on their gender. Both men and women had similar responses and perceived their skills in the same way. On the other hand, we found differences in participants' beliefs based on their educational level. In particular, volunteers or volunteers' coordinators with a university degree perceived that they 
had less competencies for the development of the actions they took in their organizations than those without a university degree. Maybe this finding implies that volunteers without university studies tend to overestimate their capabilities. According to McPherson and Rotolo (1996), the level of education has been found to be a stable predictor of volunteering.

Also, we found that the role in the sport organizations differentiate the beliefs of the volunteers about their competencies. Specifically, although all participants expressed confidence in their skills, volunteers' coordinators had stronger beliefs than volunteers. However, this finding needs to be addressed with caution since the number of volunteers' coordinators is limited. Finally, our findings indicated that volunteers or volunteers' coordinators engaged in volunteering in sport organizations for years perceived their competencies in a similar way to those who offered their voluntary action for a shorter period of time. As a result, we can conclude that, regardless of the years of involvement in volunteering, the motive to volunteer is the need to contribute to society as a whole rather than how someone perceives their skills.

\section{Conclusion}

Our study investigated the beliefs of volunteers or volunteers' coordinators about their competencies during providing volunteering services in sport organizations. According to our findings, volunteers and volunteers' coordinators had positive beliefs about their competencies. Respecting the rules of the sport organization was identified as their greatest asset, while autonomous decision-making was recognized as their less developed skill. In addition, findings showed no differences in the beliefs of volunteers or volunteer coordinators based on their gender or years of engagement in volunteering in sport organizations. On the contrary, volunteers or volunteers' coordinators with a university degree perceived that they had less competencies for volunteering in sport organizations than those without a university degree. Finally, volunteers' coordinators had stronger beliefs than volunteers. Overall, the findings of the present study have provided useful information that can be used by sport organizations in order to empower volunteers and make them more effective in their work.

\section{Acknowledgement}

This study was conducted with support from the European Commission. This publication only reflects the views of the authors, and the Commission cannot be held responsible for any use which may be made of the information contained therein.

\section{References}

Anheier, H. K., \& Salamon, L. M. (1999). Volunteering in cross-national perspective: Initial comparisons. Law and Contemporary Problems, 62(4), 43-65. doi: 10.2307/1192266

Butcher, J., \& Einolf, C. J. (2016). Volunteering: A complex social phenomenon. In J. Butcher \& C. J. Einolf (Eds.), Perspectives on volunteering. Nonprofit and civil society studies (pp. 3-26). Springer. https://doi.org/10.1007/978-3-319-39899-0_1 
Byers, T. (2009). Research on voluntary sport organisations: Established themes and emerging opportunities. International Journal of Sport Management and Marketing, 6(2), 215-228. https://doi.org/10.1504/IJSMM.2009.028803

Cnaan, R. A., Handy, F., \& Wadsworth, M. (1996). Defining who is a volunteer: Conceptual and empirical considerations. Nonprofit and Voluntary Sector Quarterly, 25(3), 364-383. https://doi.org/10.1177\%2F0899764096253006

Cuskelly, G., \& Harrington, M. (1997). Volunteers and leisure: Evidence of marginal and career volunteerism in sport. World Leisure \& Recreation, 39(3), 11-18. https://doi.org/10.1080/10261133.1997.9674073

Cuskelly, G., Hoye, R., \& Auld, C. (2006). Working with volunteers in sport: Theory and practice. Routledge.

Dunn, J., Chambers, S. K., \& Hyde, M. K. (2015). Systematic review of motives for episodic volunteering. VOLUNTAS: International Journal of Voluntary and Nonprofit Organizations, 27(1), 425-464. https://doi.org/10.1007/s11266-015-9548-4

Edwards, M. (2004). Civil society. Polity Press.

European Commission. (2014). Special Eurobarometer 412: Sport and physical activity Report. https://ec.europa.eu/commfrontoffice/publicopinion/archives/ebs/ebs_412_en.pdf

European Council. (2000). Conclusions of the Presidency. Annex IV: Declaration on the specific characteristics of sport and its social function in Europe, of which account should be taken in implementing common policies. Nice, 7-10 December 2000. https://www.europarl.europa.eu/summits/nice2_en.htm

Fairley, S., Kellett, P., \& Green, B. C. (2007). Volunteering abroad: Motives for travel to volunteer at the Athens Olympic Games. Journal of Sport Management, 21(1), 4157. https://doi.org/10.1123/jsm.21.1.41

GHK. (2010). Volunteering in the European Union: Final report submitted by GHK. Brussels: Educational, Audiovisual \& Culture Executive Agency (EAC-EA), Directorate General Education and Culture (DG EAC). https://ec.europa.eu/citizenship/pdf/doc1018_en.pdf

Gravelle, F., \& Larocque, L. (2005). Volunteerism and serious leisure: The case of the Francophone Games. World Leisure Journal, 47(1), 45-51. https://doi.org/10.1080/04419057.2005.9674385

Green, M., \& Oakley, B. (2001). Elite sport development systems and playing to win: Uniformity and diversity in international approaches. Leisure Studies, 20(4), 247-267. https://doi.org/10.1080/02614360110103598

Hustinx, L. (2008). I quit, therefore I am?: Volunteer turnover and the politics of selfactualization. Nonprofit and Voluntary Sector Quarterly, 39(2), 236-255. https://doi.org/10.1177\%2F0899764008328183

Hustinx, L., \& Lammertyn, F. (2003). Collective and reflexive styles of volunteering: A sociological modernization perspective. VOLUNTAS: International Journal of Voluntary and Nonprofit Organizations, 14(2), 167-187. https://doi.org/10.1023/A:1023948027200

Hustinx, L., Handy, F., \& Cnaan, R. A. (2011). Volunteering. In R. Taylor (Ed.), Third sector research (pp.73-90). Springer.

International Labor Organization. (2007). Manual on the measurement of volunteer work. Geneva: International Labour Office. https://www.ilo.org/wcmsp5/groups/public/--dgreports/---stat/documents/meetingdocument/wcms_100574.pdf

Kulik, L. (2006). Burnout among volunteers in the social services: The impact of gender and employment status. Journal of Community Psychology, 34(5), 541-561. https://doi.org/10.1002/jcop.20114

Lorentzen, H., \& Hustinx, L. (2007). Civic involvement and modernization. Journal of Civil Society, 3(2), 101-118. https://doi.org/10.1080/17448680701554282 
Lough, B. J., McBride, A. M., Sherraden, M. S., \& O’Hara, K. (2011). Capacity building contributions of short-term international volunteers. Journal of Community Practice, 19(2), 120-137. https://doi.org/10.1080/10705422.2011.568921

Marková, A. (2018). The "inclusive volunteering" phenomenon: Research into the volunteering of people with disabilities. Kontakt, 20(1), e48-e56.

https://doi.org/10.1016/j.kontakt.2017.10.003

McPherson, J. M., \& Rotolo, T. (1996). Testing a dynamic model of social composition: Diversity and change in voluntary groups. American Sociological Review, 61(2), 179-202. DOI: $10.2307 / 2096330$

Misener, K., Doherty, A., \& Hamm-Kerwin, S. (2010). Learning from the experiences of older adult volunteers in sport: A serious leisure perspective. Journal of Leisure Research, 42(2), 267-289. https://doi.org/10.1080/00222216.2010.11950205

Nichols, G., Tacon, R., \& Muir, A. (2012). Sports clubs' volunteers: Bonding in or bridging out? Sociology, 47(2), 350-367. http://dx.doi.org/10.1177/0038038512441278

Pearce, J. (1993). Volunteers: The organizational behavior of unpaid workers. Routledge.

Polyzoidis, P. (2006). Volunteering in social protection. Greek Letters.

Rehberg, W. (2005). Altruistic individualists: Motivations for international volunteering among young adults in Switzerland. VOLUNTAS: International Journal of Voluntary and Nonprofit Organizations, 16(2), 109-122. https://doi.org/10.1007/s11266-005-5693-5

Ringuet, C. (2012). Volunteers in sport: Motivations and commitment to volunteer roles. Aspetar Sports Medicine Journal, 1, 154-161.

https://www.aspetar.com/journal/upload/PDF/2013112511249.pdf

Ringuet-Riot, C., Cuskelly, G., Auld, C., \& Zakus, D. H. (2014). Volunteer roles, involvement and commitment in voluntary sport organizations: Evidence of core and peripheral volunteers. Sport in Society, 17(1), 116-133.

https://doi.org/10.1080/17430437.2013.828902

Salamon, L. M., \& Sokolowski, W. (2001). Volunteering in cross-national perspective: Evidence from 24 countries. Johns Hopkins Center for Civil Society Studies.

Smith, D. H. (2000). Grassroots associations. Sage.

Smith, K., Holmes, K., Haski-Leventhal, D., Cnaan, R. A., Handy, F., \& Brudney, J. L. (2010). Motivations and benefits of student volunteering: Comparing regular, occasional, and non-volunteers in five countries. Canadian Journal of Nonprofit and Social Economy Research, 1(1), 65-81. https://doi.org/10.22230/cjnser.2010v1n1a2

Sport England. (2003). Sports volunteering in England in 2002. Sport England.

Sport Wales. (2010). Sports volunteering in Wales. Sport Wales.

Sport and Recreation New Zealand (SPARC). (2006). Finding and keeping volunteers: What the research tells us. New Zealand.

Stebbins, R. A. (1996). Volunteering: A serious leisure perspective. Nonprofit and Voluntary Sector Quarterly, 25(2), 211-224. https://doi.org/10.1177\%2F0899764096252005

Steinbach, D., Guett, M., \& Freytag, G. (2012). Training 4 volunteers: Mapping strategies and good practices of human resource development for volunteers in sport organizations in Europe. https://www.researchgate.net/publication/261555350

Wilson, J. (2000). Volunteering. Annual Review of Sociology, 26(1), 215-240. https://doi.org/10.1146/annurev.soc.26.1.215

Wilson, J. (2012). Volunteerism research. Nonprofit and Voluntary Sector Quarterly, 41(2), 176-212. https://doi.org/10.1177\%2F0899764011434558 